\title{
The Need to Learn according to Psycho-Didactic Approach: Self-Determination and Student's Performance in Physical Education Realm
}

\author{
Chawki Derbali' $^{1}$ Ali Elloumi2 ${ }^{2}$, Fathi Matoussi ${ }^{3}$ \\ ${ }^{1}$ High Institute of Physical Education and Sport of Kef, University of Jenduba, Kef, Tunisia \\ ${ }^{2}$ Faculty of Human Sciences of Sfax, University of Sfax, Sfax, Tunisia \\ ${ }^{3}$ High Institute of Education and Continuing Training of Tunis, Virtual University of Tunis, Tunis, Tunisia \\ Email: derbali_chawki@yahoo.fr
}

How to cite this paper: Derbali, C., Elloumi, A., \& Matoussi, F. (2017). The Need to Learn according to Psycho-Didactic Approach: Self-Determination and Student's Performance in Physical Education Realm. Creative Education, 8, 1155-1171. https://doi.org/10.4236/ce.2017.87083

Received: May 15, 2017

Accepted: June 20, 2017

Published: June 23, 2017

Copyright (ङ 2017 by authors and Scientific Research Publishing Inc. This work is licensed under the Creative Commons Attribution International License (CC BY 4.0).

http://creativecommons.org/licenses/by/4.0/

\begin{abstract}
This case study is of a two-fold purpose: 1) to examine students' self-determination (SD) in physical education (PE) with construction and validation of (SD) Questionnaires; and 2) to analyze the relationships between students' SD and performance, in order to improve performance and self-efficacy in physical education. A first study step concerned the development of a SD Questionnaire to be answered by the chosen population. Factor analyses were conducted to determine the underlying structure of the SD. The confirmatory factor analyses were used to assess the reliability and the validity of the Questionnaire. In a second study step, correlation tools were used to evaluate relationships between SD and performance in physical education activities. Then, a deductive study was undertaken in order to test models of predictors' performance and check analyses of measured performances in physical activities. Exploratory and confirmatory factor analyses suggested that the final items version of SD Questionnaire is represented by seven variables. These have been labeled: (autonomy, self-regulation, intrinsic motivation, a motivation, strategy, attraction activity and self-efficacy). The SD items display satisfactory internal consistency values with $(\alpha=0.73)$. Overall, performance was significantly correlated with SD. The major sub-scales of (SD) are interrelated and closely tied to performance. A good correlation can be observed between self-determination domain and performance. Thus, the SD Questionnaire provides a useful method to study the student's perceptions and representations, and their intention in physical activity performance, in order to predict the self-efficacy in improving the performance and, in turn, the development of self-determination in physical education.
\end{abstract}




\section{Keywords}

Psycho-Didactics, Physical Activity, Self-Determination, Performance and Correlation

\section{Introduction}

Lack of physical practice, poor diet and obesity are the main causes of disease risks, depression and poor performance. Therefore, physical inactivity, which is a major problem in several domains of society, can affect health as well as the physical and psychological well-being. Encouraging young people to be active is what warrants the production of active adults. In this way, physical education (PE) was proposed as a space for physical and psychological development to achieve the recommended levels of skills, developed awareness of his beliefs and identifies his effectiveness. However, determining these goals requires a good understanding of oneself not only in terms of physical self-perception, but also in terms of self-determination such as motivation, autonomy, self-regulation, etc. Therefore, to achieve significant progress and be competitive in physical activity (PA), we must better understand the factors of self-determination that affect the process of student behavior.

From a psychological point of view, Ryan \& Deci (2002) argued that individuals have three basic psychological needs: autonomy (the need to approve and be the source of one's behavior), competence (through the need to interact positively with the environment), and relatedness (such as the need to perceive oneself attached to others and supported by others). If met, these three psychological needs are responsible for variations in the quality of learning in PE and the physical well-being of the student. In fact, the self-determination theory is built on the assumption that human behavior is motivated by three psychological needs: autonomy, competence, and commitment (Ryan \& Deci, 2000). Hence, enhanced perception of competence and self-determination creates a state of intrinsic motivation (Deci, 2008; Ryan \& Deci, 2006; Deci \& Ryan, 1991). The application of self-determination theory focuses on intrinsic motivation and selfregulation influences its development, and involvement in sports competitions. Feelings of competence and autonomy may motivate students to physical education sessions in order to develop competences and to practice a sport with pleasure and for no reward. However, the level of a person's intrinsic motivation may be affected by the surroundings, such as comments received after the performance, or material reward. The extrinsic motivation may be affected by anxiety, stress, and fear, because it does emphasize neither self-confidence nor selfesteem. It is, therefore, interesting to mention that the students were motivated by their own interests, abilities and desire to achieve their own objectives. In 2002, Hodgins, Yacko, Gottlieb, Goodwin and Rath noted that the college students with autonomous motivational states achieved a better performance on a 
rowing machine than those with extrinsic motivational states. Self-determination theory may show that motivation is a catalyst motor, and strengthens psychological behavior in different domains (Deci \& Ryan, 1985).

Another statement was argued by Standage et al. (2005). For these authors, students who perceive need support experienced higher levels of satisfaction of needs. Intrinsic motivation could predict need satisfaction and it was linked to results of PE-related adjustment. However, the need satisfaction negatively predicted amotivation, which was positively predictive of feelings of sadness. Multi-sample invariance testing revealed that the SEM model is largely invariant for male and female students. It was perceived that these results provide support for the theory of self-determination and confirm the implementation of the framework to the context of school PE.

Hence, it appears that, although the theory of self-determination has been applied in many areas, it is not flawless particularly as regards the conceptual and cognitive dynamics among learners in physical education and sport. So, what are the types of the recommended strategies to identify self-determination in PE?

Our present work determines a model of self-determination that could predict the physical performance of learners in physical activity. The theory of self-determination search answers about the actions of person questioning the motivation, the degree of autonomy and self-regulatory level identified. In this work, we search for a new identification of the student's self-determination in PE. We hypothesized that the new factors detailed self-determination (motivation, autonomy, self-regulation, attraction to activity, strategy and self-efficacy), could identify levels of the learner in physical education. Then, the interaction between students' self-determination and performance will improve performance and self-efficiency in physical education. The case study includes a first step that examined the factorial validity and the confirmatory factorial validity of the (SD Questionnaire) which contained several new items and new sub-scales. The second step is introduced to analyse the relationships between students' self-determination and performance, in order to improve performance and self-efficacy in physical education.

\section{Material and Methodology}

For the first study step of the instrument factor analysis, a questionnaire was the fundamental basis that concerned a certain number of participants.

\subsection{Questionnaire's Subscales}

Strategy. Strategies refer to a set of actions or observable and unobservable ways (behaviors, thoughts, techniques, and tactics) used by a person with intent and adjusted for variable situations. (Example of item: If you are in front of a difficult situation, you know how, when and by what you solve your problem).

Intrinsic motivation. Intrinsic motivation is always defined as a stimulation that drives a person to adopt or change a behavior for her own internal satisfaction by an interest or enjoyment in the task itself or in doing an activity for his 
inherent fulfillment. Intrinsic motivation is usually self-applied, and resilience from a direct relationship between the individual and the situation. (Example of item: I'm satisfied to do this behavior, because I like the feelings of success and enjoyment that come from doing right a sport's exercise).

Autonomy. Autonomy is the quality of having the ability or tendency to function independently. It is the ability to make his own decisions about what to do rather than being influenced by someone else or told what to do and is often used as the basis for determining moral responsibility for one's actions. (Example of item: I self-direct my action and I control my behavior).

Self-regulation. Self-regulation is the ability to develop, put into practice, and flexibly maintain planned behavior in order to achieve one's goals. The Self-Regulation refers to the self-directive process through which learners transform their mental abilities into task related skills (Zimmerman \& Schunk, 2001). (Example of item: I am able to accomplish objectives, I set for myself).

Self-efficacy. Self-efficacy has been described as the belief that one is capable of performing in a certain manner to attain certain goals. It is a belief that one has the capabilities to execute the courses of actions required to manage prospective situations, and a belief in one's own ability to perform a task. (Example of item: I am certain that I can do well sport's exercises, be perform and succeed, even if I faced several problems).

Attraction activity. The attraction to the physical activity can be defined as the vigorous acceptance and the link of a person to the activity. It means that students reported their liking for the sports activity and their preferences for engaging in activities. (Example of item: Several times a week I do physical activity and play hard enough to breathe hard-to-huff and puff).

Amotivation. Amotivation refers to the inability or unwillingness to participate in normal situation or activity. It is a psychological condition associated with diminished inspiration to participate in physical activities or social situations, with lapses in apathy caused by an external event or lack of something. (Example of item: I am not satisfied during practice of sport's activities).

\subsection{Participants and Procedure}

179 participants volunteered for the study (109 girls and 70 boys), aged between 15 and 18. They continually attend PE classes. They were informed that the questionnaire is anonymous and is not a test. Each student should mention his/ her age and gender for the sake of research. All data remains confidential. Participants were, then, given 10 to 15 minutes to complete the questionnaire. In this study, questionnaires were designed to reveal several variables among students (attraction to the activity, self-efficacy, autonomy, intrinsic motivation, amotivation, self-regulation and strategy).

The questionnaire was developed in function of self-determination's theoretical data, what are the components of the process of self-determination in physical education who carried out, namely: (attraction to the activity, self-efficacy, autonomy, intrinsic motivation, amotivation, self-regulation and strategy). The 
questionnaire comprises five scales: completely disagree, few agree, moderately agree, strongly agree and totally agree, unlike many questionnaires containing only the words Yes, No which may influence responses because the respondent can't answer such as he really hesitated between Yes and No. In this logic filling the questionnaire by the students responded to the Likert scale was adapted to five points, with [1]: "completely disagree", [5]: "totally agree" on both ends of the scale. These levels of scale will give student more opportunities to better understand his concerns and properly. Completely disagree and few agree in fact are considered as negative, whereas strongly and completely agree as positive. We also clarified that non-response from one of the elements will be considered non-existent. To measure the responses, we quantified the scale, [1] completely disagree, [2] for few agree, [3] for moderately agree, [4] for Strongly Agree and [5] for completely agree. This will not only capture data (Access application developed, see below), but also to treat them through specific functions.

In the second study step of Confirmatory factor analysis of the instrument, the objective of this study was threefold: 1) to determine the confirmation of the factor structure of the questionnaire and the internal consistency between the five factors of the instrument for a larger population; 2) to validate the relationships between the subscales defined in the first study and 3) to evaluate the influence of gender on students' responses in this questionnaire. For these purposes, the sample consisted of 314 students (boys and 128 girls 186). The age is between 15 and 18 years old and attends regular Physical Education at school. The procedure of the questionnaire is similar to that of the first study.

\subsection{Analysis of the Temporal Fidelity of the Tool}

This study seeks two objectives:

-Test the temporal fidelity of the instrument.

-Confirm the internal consistency of each parameter of the questionnaire.

For this, the study implied 87 volunteers ( 49 girls and 38 boys). The age of the population varies between 15 and 18. They participate in meetings of EPS. The approach of the questionnaire, similar to those of previous studies, is repeated twice on the same population. The awarding of the second questionnaire, it was after ten days of the first (test $2=$ initial test +10 days).

\subsection{Analysis of Construct Validity}

The objective of this study is to assess the construct validity by analyzing constructs of self-determination among the students. The sample was constructed of 323 participants (159 girls and 164 boys), aged between 15 and 18. They attend Physical Education at school. The approach of the questionnaire is similar to that used in previous studies. In fact, students have responded to factors measuring (attraction activity, self-efficacy, autonomy, intrinsic motivation, amotivation, and self- regulation and strategy).

This study builds on the work of construction and validation of questionnaires on the self-determination of students on the PE. As the theories of repre- 
sentations of students' sports practices.

Filling the questionnaire by the students responded to the Likert scale adapted five points. [1]: not at all in agreement, [5]: totally agree.

\subsection{The Correlation between the Subscales of Self-Determination and Measured Performances in Physical Activities}

The purpose of this study was to determine the relation between self-determination and measured performance in physical activities. The sample was constructed of 179 participants (109 girls; 70 boys), aged between 15 and 18 . They attend Physical Education at school. After completing each cycle of physical activity, an evaluation test was conducted with support of student performance in (Gymnastics, Shot Put, Basketball and Long Jump). The evaluation was determined using an evaluation grid for each activity.

The height and the weight were measured for each student in order to calculate their body mass index BMI (weight in kilograms divided by the square of height in meters).

\section{Results and Discussion}

\subsection{For the First Study Step of the Instrument Factor Analysis}

The observation of the factor structure was determined using the varimax rotation and throw results of standardized loadings of exploratory factor analysis on the Self-determination in Table 1. This analysis is for the seven factors of the design students on the self-determination in physical education at school. We could consider that the eigen value greater than 1 (Guttman, 1954), as it develops $57 \%$ of the total variance. This value is adequate according to (Gorsuch, 1983).

The observation of the factor structure was determined using the varimax rotation and through the results of standardized loadings of exploratory factor analysis on Self-determination. This part of search, analysis the seven factors of the student's self-determination in physical education. We could consider that the Eigen value is greater than 1 (Guttman, 1954), as it develops 57\% of the total variance. This value is adequate according to (Gorsuch, 1983).

The results in Table 2 show that the seven factors of the conceptions of students showing positive saturation values are higher than 0.53 . This is given by (Conroy et al., 2003). The results indicate very high average values on the pull factors: in attraction to the activity, self-efficacy, autonomy, intrinsic motivation, amotivation, self-regulation and strategy. Although, the index amotivation does not reach the average, the average values associated to the other factor of selfdetermination are close to the average of the scale. Internal consistencies for the seven sub-scales are found to vary between 0.846 and 0.972 . Hence the alpha values (Cronbach, 1951) are acceptable and approved by (Nunnally, 1978). Therefore, the results reported in Table 2 determine the nature of correlation between different sub-scales, which determines the different components of selfdetermination of students in physical education and sport. Generally, the correlation indices show significant relationships between the seven factors studied. 
Table 1. Results of standardized loadings of exploratory factor analysis on the SD.

\begin{tabular}{|c|c|c|c|c|c|c|c|}
\hline \multicolumn{8}{|c|}{ Factors } \\
\hline $\begin{array}{l}\text { Items measuring } \\
\text { self-determination } \\
\text { of students }\end{array}$ & $\begin{array}{l}\text { Attraction } \\
\text { to the activity }\end{array}$ & Self-efficacy & Autonomy & $\begin{array}{c}\text { Intrinsic } \\
\text { Motivation }\end{array}$ & Amotivation & Self-regulation & Strategy \\
\hline I1 & .554 & & & & & & \\
\hline $\mathrm{I} 2$ & .963 & & & & & & \\
\hline $\mathrm{I} 3$ & .918 & & & & & & \\
\hline $\mathrm{I} 4$ & .933 & & & & & & \\
\hline I5 & .929 & & & & & & \\
\hline I6 & & .847 & & & & & \\
\hline I7 & & .717 & & & & & \\
\hline I8 & & .959 & & & & & \\
\hline I9 & & .957 & & & & & \\
\hline $\mathrm{I} 10$ & & .967 & & & & & \\
\hline I11 & & .827 & & & & & \\
\hline $\mathrm{I} 12$ & & & .815 & & & & \\
\hline $\mathrm{I} 13$ & & & .958 & & & & \\
\hline $\mathrm{I} 14$ & & & .957 & & & & \\
\hline $\mathrm{I} 15$ & & & .830 & & & & \\
\hline I16 & & & & .880 & & & \\
\hline I17 & & & & .947 & & & \\
\hline $\mathrm{I} 18$ & & & & .657 & & & \\
\hline I19 & & & & .953 & & & \\
\hline $\mathrm{I} 20$ & & & & & .627 & & \\
\hline I 21 & & & & & .532 & & \\
\hline I 22 & & & & & .753 & & \\
\hline $\mathrm{I} 23$ & & & & & .774 & & \\
\hline I 24 & & & & & & .892 & \\
\hline $\mathrm{I} 25$ & & & & & & .642 & \\
\hline I 26 & & & & & & .929 & \\
\hline I 27 & & & & & & .932 & \\
\hline $\mathrm{I} 28$ & & & & & & & .718 \\
\hline I 29 & & & & & & & .906 \\
\hline I30 & & & & & & & .796 \\
\hline
\end{tabular}

Note. $\mathrm{N}=$ Notes. $\mathrm{N}=79 ; \mathrm{I}=$ item, there is only the factor saturations $>$ à 0.5 . 
Table 2. Means, standard deviation, internal consistency and correlation between sub-scales.

\begin{tabular}{|c|c|c|c|c|c|c|c|c|c|c|}
\hline \multicolumn{11}{|c|}{ Sub-Scales } \\
\hline & $\mathrm{M}$ & $\mathrm{SD}$ & $\begin{array}{l}\text { Cronbach } \\
\text { Alpha }\end{array}$ & 1 & 2 & 3 & 4 & 5 & 6 & 7 \\
\hline Attraction to the activity & 3.24 & .972 & 7.95 & - & & & & & & \\
\hline Self-efficacy & 3.20 & 1.013 & .972 & $.827^{\star *}$ & - & & & & & \\
\hline Autonomy & 3.31 & 1.062 & 8.95 & $.725^{\star *}$ & $.816^{* *}$ & - & & & & \\
\hline Intrinsic Motivation & 3.41 & 1.048 & .944 & $.695^{* *}$ & $.695^{* *}$ & $.756^{* *}$ & - & & & \\
\hline Amotivation & 1.74 & 1.067 & 846. & $-.443^{\star *}$ & $-.456^{\star *}$ & $-.440^{* *}$ & $-.561^{* *}$ & - & & \\
\hline Self-regulation & 3.39 & 1.075 & .939 & $.249^{* *}$ & $.196^{* *}$ & $.341^{* *}$ & $.460^{* *}$ & $-.186^{*}$ & - & \\
\hline Strategy & 3.25 & 1.095 & .879 & $.611^{* *}$ & $.627^{* *}$ & $.590^{* *}$ & $.562^{* *}$ & $-.405^{* *}$ & $.242^{* *}$ & - \\
\hline
\end{tabular}

Note. $\mathrm{N}=179 ; p<0.001$.

\subsection{Case Study 2}

\subsubsection{Confirmatory Factor Analysis and Internal Consistency}

Confirmatory factor analysis and internal consistency of the measurement tool were conducted confirmatory factor analysis using Amos, Lisrel (Arbuckle \& Wothke, 1999). Thus, we have examined compared to study 1 link in the results obtained in both studies. However, the hypothetical model is that any statement of each factor of the instrument should meet on their variable-specific confidence. Therefore, a correlational matrix is obtained within the responses examined in terms of 30 variables observed (Chou \& Benter, 1995). Thus, the results confirm the factorial validity of the hypothetical model through $\mathrm{x}^{2}(38)=$ $196.34, p<.001, \mathrm{CFI}=.92, \mathrm{GFI}=.91, \mathrm{RMSEA}=.06$; is the confidence interval for RMSEA $=.056 / .076, .045=$ DALE, DALE. Moreover, the estimated standardized coefficients are above .57 and they are significant.

\subsubsection{Assessing the Influence of Sex}

From the responses on the questionnaire, we tested the effect of sex through the invariance of factor structure between the sexes, by studying three variables: factor structure, error variance and correlation factor. These parameters confirm the null hypothesis $\Delta \mathrm{X}^{2}$ no significant parameters. And thus, we deduce the factorial invariance between the two kinds male and female. This result is consistent with published data (Elliot \& McGregor, 2001). The unvaried tests were performed on all factors representing the sub-scales of the self-determination in PE. As the first clue, we found that boys are superior to scores obtained from those of girls. For boys $\mathrm{M}=3.91$ while for girls $\mathrm{M}=3.24$. Then, to approach the attraction activity $\mathrm{F}(1.32)=22.37, p<.001$. Also, the approach of self-regulation is that $\mathrm{F}(1.41)=23.18, p<.001$. At the end we have noted that the approach of self-efficacy shows that $\mathrm{F}(1.65)=32.64, p<.001$.

\subsection{Case study 3}

The results of the correlational analysis confirmed the temporal stability of the 
measurement tool of design students. The Pearson correlation obtained are higher than 0.60 . The latter was confirmed by a study conformist (Duda et al., 1998). The internal consistencies of each factor of students' conceptions were similar to those of the 30 observed responses. In addition these alpha values are between 0.70 and 0.93 . And this confirms previous studies.

\subsection{Study 4}

This study showed that the Cronbach's alpha coefficients of subscales (attraction to the activity, self-efficacy, autonomy, intrinsic motivation, amotivation, selfregulation efficacy and strategy) are respectively $0.95,0.97,0.95,0.94,0.84,0.93$, and 0.87 . The results show that the subscales identified themselves as valid predictors of student representation on their self-determination on the practice of physical activities and sports in physical education and sports.

\section{Discussion of the Confirmatory Factor Analysis}

The objective of this complementary study was threefold: firstly, determine the confirmation of the factor structure of the questionnaire and the internal consistency between the five factors of the instrument for a larger population. Secondly, it aims at validating the relationships between the subscales defined in the first study. Finally, it seeks to evaluate the influence of gender on students' responses in this questionnaire. The sample consisted of 314 students (boys and 128 girls 186), aged between 15 and 18 years old and attends regular physical education classes at school. The procedure of the questionnaire is similar to that of the first study. It was built on the work of construction and validation of the questionnaires on the students' self-determination in PE, based on the theories of representations of students' sports practices. Filling the questionnaire by the students responded to the Likert scale with [1]: "not at all in agreement", and [5]: "totally agree" on both ends of the scale.

We conducted confirmatory factor analysis using the software Lisrel 8.4. Thus, we have examined, compared to study 1, the link between the results obtained in both studies. However, the hypothetical model is that any statement of each factor of the instrument should meet their specific confidence variables. Therefore, a correlational matrix is obtained within the responses examined in terms of 30 variables observed (Chou \& Benter, 1995). Thus, the results confirm the factorial validity of the hypothetical model through (X2, $p<.001)$; (CFI, GFI, NNFI are adjusted between 0.91 and 0.95 ) and (RMSEA ranging from 0.05 to 0.07). Moreover, the estimated standardized coefficients are above .57 and they are significant. This study showed that the Cronbach's alpha coefficients of sub-scales (attraction to the activity, self-efficacy, autonomy, intrinsic motivation, amotivation, self-regulation and strategy) are respectively $0.95,0.97,0.95$, $0.94,0.84,0.93$, and 0.87 . The results show that these sub-scales identified themselves as valid predictors of students' representation on their self-determination with the practice of physical activities in physical education. The findings call for the promotion of self-determined motivation in PE in order to enhance students' positive experiences and engagement rates (Figure 1). 


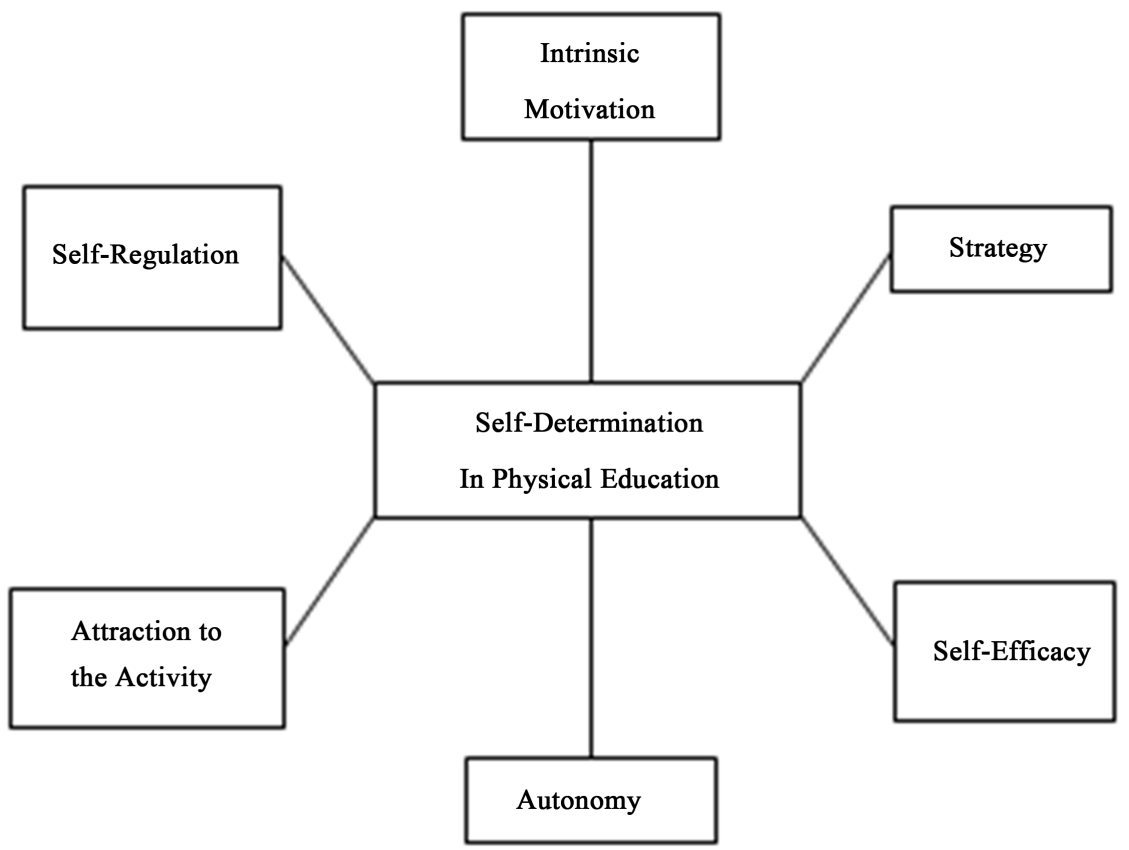

Figure 1. The model of the self-determination in physical education including: Intrinsic motivation, strategy, autonomy, self-regulation, attraction to the activity and self-efficacy.

The strategy is to establish the goals and targets long-term fundamentals of an organization can choose the mode of action and resource allocation that will accomplish these goals and objectives. The strategy commits all resources held by the student and this over a long period; the strategy involves first determining the goals of the learner who then shares declined to meet these objectives or well reach his goal; finally, the strategy determines the means to implement to achieve the objectives. This is ultimately up to answer three questions at once: What to produce? How to achieve this production? With what means should I do?

Among researchers, Weinstein (1994) have shown that students who do well are those courses that use effective learning strategies for successfully completing the various activities offered to them. The necessity to achieve a goal need to be motivated and specially, intrinsically motivated. The self-determination of the intrinsic motivation is very important factor in the design of a learning or training activity. Scholar is likely to be intrinsically motivated if he attributes his educational results to arousal internal factors that he can control. When intrinsically motivated, the individual is moved to act for the fun or challenge involved rather than because of external products, pressures or reward. Intrinsic motivation does not mean, however, that a person will not seek rewards. It just means that such external rewards are not enough to keep a person motivated. An intrinsically motivated student, for example, may want to get a good grade or performance on an assignment or task, but if the assignment does not interest that student, the possibility of a good grade is not enough to maintain that student's motivation to put any effort into the sport's exercise. An intrinsically motivated pupil will work on a sport's exercise or on a solution to a problem, for example, 
because it is enjoyable and the challenge of finding a solution is giving a sense of pleasure. By intrinsic motivation we mean a process of activation and fulfillment in which the rewards come from carrying out an activity rather from a result of the activity. We speak of the rewards being intrinsic to a task rather than the task being a means to an end that is rewarded or satisfying. Intrinsic motivation leans more to be appetitive, new information arousing a small interest encouraging to a desire for more. For creativity, in order to succeed, students must be permitted to have a degree of freedom to select their approaches to their work, to fail sometimes without mockery or punishment, to extend their horizons in terms of working with others who will share their knowledge, and to feel comfortable knowing that the organization supports their work with the requisite resources. Otherwise, they will keep the safe trying various approaches to solving problems. So in addition to self-determination a possible strategy and to be intrinsically motivated or satisfied, it is important that the learner can self-determined his regulation in the process of achieving a goal or a result. Since the capacity to selfregulation has been considered as a wanted quality because of its constructive property on behavior and the achievement of ability (Reid, 1993). The Self-Regulation refers to the self-directive process through which learners transform their mental abilities into task related skills (Zimmerman \& Schunk, 2001). The students use this procedure in order to direct and arrange their beliefs and adapt them into skills used for learning. Self-regulation is the process of permanent monitoring progress on the way to a goal, ensuring result, and reorganizing failed work (Berk, 2003). For being self-regulated students, they necessitate to be conscious of their own reflection process, and be motivated to vigorously take part in their own learning process (Zimmerman \& Schunk, 2001). We use the Self-regulation because of the effects that it has on educational and behavioral results in PE. Students need to view learning as an activity that they do for themselves in a practical technique, rather than viewing learning as a covert event that happens to them as an outcome of education (Zimmerman \& Schunk, 2001). So, allowing students to get a more active function in their learning puts learners in change and continuous evolution. Successful students use self-regulation to effectively and efficiently accomplish a work. They will regulate different strategies and monitor the effectiveness of that strategy while evaluating and determining the next course of action. Through the use of strategies and self-regulation, performance can be significantly enhanced. In addition to that, the students can believe in his success and in his efficacy. In fact, the feeling of self-worth and competence to intrinsically motivate is individual. So, the Self-efficacy is related to a person's ability to have optimistic beliefs, but in contrast to other features of optimism, perceived self-efficacy explicitly refers to student's ability to deal with challenging encounters. This concept was used by Bandura (1977), as the expectation of success in a given situation. These cognitive expectations may play a major role in determining behavior and performance in that situation in physical education. Additionally, it builds on personal past experiences of mastery. Beside, self- efficacy is a concept which refers to 
being able to picture yourself achieving what it is learner want to achieve at the level he want to achieve it. In this case, Bandura would put an academic self-efficacy referring to people's convictions about their own capabilities for successfully executing a course of action that leads to a desired outcome. Although, self-efficacy concerns learner's judgment of his capabilities based on mastery criteria. It's a sense of his competence within a specific framework. It focuses on pupil's own assessment of his own abilities in relation to goals and standards rather than in comparison with others' capabilities. In study after study, high academic self-efficacy is shown to be a very strong predictor of academic achievement. Increased self-efficacy is accompanied by improved intrinsic motivation, the ability to maintain levels of motivation and achievementoriented behaviors, perseverance in the face of problems, and improved difficulty solving. Meanwhile, self-efficacy refers to an individual's believes about his/ her agency or ability to successful perform various works in sports activities. Considerable study has suggested that alterations in self-efficacy beliefs are intimately associated with changes in actual competence and behavior. following the path of the self-determination in physical education, autonomy underpins the individualization of instruction, the development of patterns of self-directed learning and of the methodology of self-access, as well as implying some degree of learner training. In fact, the autonomy education refers to a learner's capacity to take charge of both the strategy and content of learning, and is obviously predicated on an assumption that the educational environment will provide the freedom for him or her to do so. Furthermore, autonomy is the ability to take charge of one's own learning. It is a situation in which the learner is totally responsible for all the decisions concerned with his/her learning and the implementation of those decisions, with making use of self-assessment. Although, according to motivational theory and physical self-perceptions are fundamental to the intrinsic desire to engage in physical activity through play, games, and sport. So, attraction to physical activity is an individual attachment to the activity with engagement in play, games and sports. Within the framework of the self-determination theory, Anthony J. et al. wanted to find out if autonomy, perceived competence, and relatedness mediated the relationship between self-perceived support coaching and guiding athletes' motivation. These results highlight the positive impact of coaching behavior motivation and self- support that could strengthen, in turn, the theory of self-determination (Anthony et al., 2007).

\subsection{Study 5}

This article is interested in identifying, firstly, the relations between self-determination and measured performances. Secondly, the present work examines the correlation between self-determination and performances. Finally, we search to develop perceived competences, physical self-efficacy, strategies of students. On the other hand, we seek to help and encourage students to improve their level in PE with archiving new abilities and getting better performances in PA. So, pleasure, performance, personal development and academic maturity, are indis- 
pensable objectives to be achieved by our students. Relationships between academic achievement in PE program and self-determination have been examined, based on a systematic measured performance and self-determined perception.

Assessment protocol. The performance measure of 4 activities (Gymnastic, Shot Put, Basket-Ball, and Long Jump) was done using evaluation grid of learning phases in each activity. Teacher referring to physical education program, developed observation tools and performance-based assessments of student learning.

On the one hand, Table 3 showed negative correlation between body mass index and performance in physical activities despite, there is a significant correlation between performance and height. In addition, there is negative signification between performance and weight. The principal reason is that girls have body fat, were as boys have BMI under normal average.

On the other hand, data analysis showed a significant multivariate effect between of treatment, which could be attributed to self-determination, subscales (attraction to the activity, self-efficacy, autonomy, intrinsic motivation, amotivation, self-regulation and strategy). Despite, there is a negative signification between amotivation from SD and physical activities $(p>0.05)$, all other sub-scales from the both PSP and SD were significantly correlated with each other. The correlation ranged from 0.933 to 0.188 with the performance being in several physical activities such as Gymnastic, Shot Put, Basket-Ball and Long Jump.

\section{Concluding Remarks}

The aim of this article was to identify the relationships between self-determina-

Table 3. Correlation coefficients of Pearson between the sub-scales of SD and measured performances in physical activities.

\begin{tabular}{cccccc}
\hline Pearson Correlations & Gymnastic & Shot Put & Basket-Ball & Long Jump & $\begin{array}{c}\text { Average } \\
\text { Performance }\end{array}$ \\
Age & $.193^{* *}$ & .040 & .055 & .063 & .098 \\
Weight & $-.253^{* *}$ & $-.293^{* *}$ & $-.352^{* *}$ & $-.359^{* *}$ & $-.345-^{* *}$ \\
Height & $.199^{* *}$ & $.258^{* *}$ & $.229^{* *}$ & $.165^{*}$ & $.235^{* *}$ \\
IMC & $-.341^{* *}$ & $-.418^{* *}$ & $-.460^{* *}$ & $-.438^{* *}$ & $-.455^{* *}$ \\
Attraction Activity & $.715^{* *}$ & $.627^{* *}$ & $.707^{* *}$ & $.793^{* *}$ & $.781^{* *}$ \\
Self- Efficacy & $.825^{* *}$ & $.722^{* *}$ & $.830^{* *}$ & $.933^{* *}$ & $.910^{* *}$ \\
Autonomy & $.673^{* *}$ & $.586^{* *}$ & $.696^{* *}$ & $.758^{* *}$ & $.745^{* *}$ \\
Intrinsic Motivation & $.627^{* *}$ & $.502^{* *}$ & $.555^{* *}$ & $.665^{* *}$ & $.646^{* *}$ \\
Amotivation & $-.424^{* *}$ & $-.272^{* *}$ & $-.306^{* *}$ & $-.376^{* *}$ & $-.380^{* *}$ \\
Self-Regulation & $.188^{*}$ & $.226^{* *}$ & $.222^{* *}$ & $.213^{* *}$ & $.233^{* *}$ \\
Strategy & $.539^{* *}$ & $.475^{* *}$ & $.580^{* *}$ & $.598^{* *}$ & $.602^{* *}$ \\
\hline
\end{tabular}

Notes. ${ }^{\star}$ Correlation is significant at $p<0.05 .{ }^{*}$ Correlation is significant at $p<0.001$. 
tion and performance. Certainly, the prediction of physical self-efficacy of students in the field of physical education and sports highlights several factors such as self-concept, many forms of self-knowledge and feelings of self-evaluation, global self-perception and self-esteem. All these are structured hierarchically, with a comprehensive self-concept on top of the hierarchy. In contrast, self-efficacy items focus exclusively on the expectations of performance on specific tasks long before the responses to the scenarios and the estimation of future performance are often correlated. In addition to that, the determination of the indirect effects of found results, provided support in self-efficacy. Lastly, the prediction of the self-efficacy was supported between 5 predictors, such as performance, strategy, attraction activity, autonomy, motivation and self-regulation. Then, measures of performance are not only different, but they are conceptually related to deep structures. In line with literature results (Lubans et al., 2016; Derbali et al., 2015a) these self-determined factors were examined as potential mediating mechanisms of the intervention effect.

The change in autonomous self-regulation, in turn, predicted students' performance in the course. Further, motivation and physical competence also predicted course performance directly, although differences in the initial level of students' autonomous self-regulation has moderated effect, with strategy; and this is strongly related to the academic performance of students who are good at autonomous self-regulation (Zimmerman \& Schunk, 2001).

The students' perceptions and strategies identified have a positive effect on their own self-efficacy; and this relationship was mediated by their reported satisfaction of autonomy and perceived skills. The importance of promoting an adaptive motivational climate for students is discussed referring to self-determination theory. This theory has been demonstrated that there were effects of age and level of physical activity involvement on physical self-perceptions, selfdetermination and performance in Tunisian teenagers. Further, there is an effect of interaction between gender (males vs. females) and physical activity practice on performance. It has been proven that males who do sport have higher scores in sport competence, physical condition and performance than females. In addition to the physical education courses, those who participated in physical activity once a week or less had lower scores in sport competence, physical condition and resistance than those who participated in physical activity more than 3 times a week. Those who participated in physical activity more than 4 times a week had higher scores in performance, sport competence, physical condition and resistance than those who participated in physical activity only twice a week. The implications of these findings of measured performance confirm that physical self-perception and self-determination can predict performance in physical education. According to Lalande et al. (2017), it appears important to think through two distinct causes of need satisfaction, inside and outside the passionate activity, when examining determinants of optimal and less optimal forms of activity engagement. And the development of these concepts is discussed in this paper.

Thus, it is important to mention that the physical self-efficacy beliefs are, pri- 
marily, mediated by self-efficacy depending on the physical self-perception to identify a comprehensive physical image. This study was confirmed by (Standage \& Ryan, 2012; Derbali et al. 2015b). The Keys of meditation and self-assessment require a determination based on a control strategy with a well-developed self-esteem depending on partaking PA. Another concept was proven to deeply contribute to the construction of physical self-efficacy that is perceived control, which represented the control situation. The perception of control is to know whether the results are verified by behavior or by external forces, hence the interest is that internal locus of control should support ongoing self-directed from action of internal control, whereas external locus of control shouldn't be discouraged (Rotter, 1966). Hence, the beliefs of physical self-efficacy can predict the evolution of academic success previously. While tasks (activities) are not specific, at least the field (sport and physical education) is clear. Here, we seek self-efficacy in physical domain of physical education, the ability to measure performance of the learners proposed. Thus, the physical self-efficacy, which depends on self-determination, is different from self-efficacy, in the area studied and the performance achieved.

Finally, the results from this search in PE point out the need for additional research in order to find valid instruments for assessing the self-determination more precisely in several domains. On one hand, this research is considered necessary by using these instruments in order to find out the factorial validity of the proposed seven sub-scales of self-determination and to examine its factorial structure and invariance across our population. On the other hand, if more studies reproduce these results, then the items of the instrument may need to be revised with other population in order to hold the same connotation for males and females. While, this construct could be used, in order to increase yields on PA produced a short-term development in self-concept among young people. Furthermore, self-determination could improve performance, develop motor ability, enhance cognitive reflection and change the physical efficiency in physical education.

\section{References}

Amorosea, A. J., \& Anderson-Butcherb, D. (2007). Autonomy-Supportive Coaching and Self-Determined Motivation in High School and College Athletes: A Test of Self-Determination Theory. Psychology of Sport and Exercise, 8, 654-670.

Arbuckle, J. L., \& Wothke, W. (1999). Amos 4.0 User's Guide. Chicago, IL: SPSS.

Bandura, A. (1977). Self-Efficacy: Toward a Unifying Theory of Behavioral Change. Psychological Review, 84, 191-215. https://doi.org/10.1037/0033-295X.84.2.191

Berk, L. E. (2003). Child development. Boston, MA: Allyn and Bacon.

Conroy, W. G., Liu, Z., Nai, Q., Coggan, J. S., \& Berg, D. K. (2003). PDZ-Containing Proteins Provide a Functional Postsynaptic Scaffold for Nicotinic Receptors in Neurons. Neuron, 38, 759-771.

Chou, C. P., \& Bentler, P. M. (1995). Estimates and Tests in Structural Equation Modeling. In Rick H.

Cronbach, L. J. (1951). Coefficient Alpha and the Internal Structure of Tests. Psycholo- 
gist, 37, 122-147. https://doi.org/10.1007/bf02310555

Derbali, C., Ben Jannet, Z., \& Elloumi, A. (2015a). Physical Self-Perception and Sport's Activity Applied in Physical Education Context: The Self-Efficacy of Achievement Performance. International Journal of Advanced Sport Sciences Research, 3, 482-497.

Derbali, C., Elloumi, A., \& Matoussi, F. (2015b). Didactics of Physical Education: The Case of Motivational Students Profiles in Pole Vaulting Performance. Creative Education, 6, 1349-1359. https://doi.org/10.4236/ce.2015.612136

Deci, E. L. (2008). Self-Determination Theory: A Macrotheory of Human Motivation, Development and Health. Canadian Psychology, 49, 182-185. https://doi.org/10.1037/a0012801

Deci, E. L., \& Ryan, R. M. (1991). A Motivational Approach to Self: Integration in Personality. In R. Dienstbier, \& N. E. Lincoln (Eds.), Nebraska Symposium on Motivation: Perspectives on Motivation (pp. 237-288, vol. 38). Lincoln, NE: University of Nebraska Press.

Deci, E. L., \& Ryan, R. M. (1985). Intrinsic Motivation and Self-Determination in Human Behavior. New York, NY: Plenum. https://doi.org/10.1007/978-1-4899-2271-7

Duda, J. L., \& Whitehead, J. (1998). Measurement of Goal Perspectives in the Physical Domain. In J. Duda (Ed.), Advances in Sport and Exercise Psychology Measurement (pp. 21-48). Morgantown, WV: Fitness Information Technologies.

Elliot, A. J., \& McGregor, H. A. (2001). A 2 X 2 Achievement Goal Framework. Journal of Personality and Social Psychology, 80, 501-519.

https://doi.org/10.1037/0022-3514.80.3.501

Gorsuch, R. L. (1983). Factor Analysis (2nd ed.). Hillsdale, NJ: Erlbaum.

Guttman (1954). Some Necessary Conditions for Common-Factor Analysis. Psychometrika. https://doi.org/10.1007/BF02289162

Hodgins, H. S., Yacko, H. A., Gottlieb, E., Goodwin, G., \& Rath, P. (2002). Autonomy and Engaging versus Defending against Experience. Unpublished Manuscript, Skidmore College.

Lalande, D. R., Vallerand, R. J., Lafrenière, M.-A. K., Verner-Filion, J., Laurent, F.-A., Forest, J., \& Paquet, Y. (2017). Obsessive Passion: A Compensatory Response to Unsatisfied Needs. Journal of Personality, 85, 163-178.

https://doi.org/10.1111/jopy.12229

Lubans, D. R., Smith, J. J., Morgan, P. J., Beauchamp, M. R., Miller, A., Lonsdale, C., Parker, P., \& Dally, K. (2016). Mediators of Psychological Well-Being in Adolescent Boys. Journal of Adolescent Health, 58, 230-236.

Nunnally, J. C. (1978). Psychometric Theory. New York, NY: McGraw-Hill.

Reid, B. (1993). But We're Doing It Already. In Exploring a Response to the Concept of Reflective Practice in Order to Improve Its Facilitation Nurse Education Today (pp. 305-309).

Rotter, J. (1966). Generalized Expectancies for Internal versus External Control of Reinforcements. Psychological Monographs, 80, Article No. 609. https://doi.org/10.1037/h0092976

Ryan, R. M., \& Deci, E. L. (2006). Self-Regulation and the Problem of Human Autonomy: Does Psychology Need Choice, Self-Determination, and Will? Journal of Personality, 74, 1557-1586. https://doi.org/10.1111/j.1467-6494.2006.00420.x

Ryan, R. M., \& Deci, E. L. (2002). An Overview of Self-Determination Theory. In E. L. Deci, \& R. M. Ryan (Eds.), Handbook of Self-Determination Research (pp. 3-33). 
Rochester, NY: University of Rochester Press.

Ryan, R. M., \& Deci, E. L. (2000). Self-Determination Theory and the Facilitation of Intrinsic Motivation, Social Development, and Well-Being. American Psychologist, 55, 68-78. https://doi.org/10.1037/0003-066X.55.1.68

Standage, M., \& Ryan, R. M. (2012). Self-Determination Theory and Exercise Motivation: Facilitating Self-Regulatory Processes to Support and Maintain Health and Well-Being. In G. C. Roberts, \& D. C. Treasure (Eds.), Advances in Motivation in Sport and Exercise (pp. 233-270). Champaign, IL: Human Kinetics.

Standage, M., Duda, J. L., \& Ntoumanis, N. (2005). A Test of Self-Determination Theory in School Physical Education. British Journal of Educational Psychology, 75, 411-433. https://doi.org/10.1348/000709904X22359

Weinstein, C. E. (1994). Strategic Learning/Strategic Teaching: Flip Sides of a Coin. In P. R. Pintrich, D. R. Brown, \& C. E. Weinstein (Eds.), Student Motivation, Cognition, and Learning: Essays in Honor of Wilbert J. McKeachie (pp. 257-273). Hillsdale, NJ: Lawrence Erlbaum.

Zimmerman, B. J., \& Schunk, D. H. (2001). Self-Regulated Learning and Academic Achievement: Theoretical Perspectives (2nd ed.). Mahwah, NJ: Erlbaum.

\section{Submit or recommend next manuscript to SCIRP and we will provide best} service for you:

Accepting pre-submission inquiries through Email, Facebook, LinkedIn, Twitter, etc. A wide selection of journals (inclusive of 9 subjects, more than 200 journals) Providing 24-hour high-quality service User-friendly online submission system Fair and swift peer-review system Efficient typesetting and proofreading procedure Display of the result of downloads and visits, as well as the number of cited articles Maximum dissemination of your research work

Submit your manuscript at: http://papersubmission.scirp.org/

Or contact ce@scirp.org 